\section{Transient Heterologous Gene Expression Methods for Poison Ivy Leaf and Cotyledon Tissues}

\author{
Christopher C. Dickinson \\ Department of Plant Pathology, Physiology, and Weed Science, Virginia \\ Tech, 220 Ag Quad Lane, Blacksburg, VA 24061
}

\author{
Alexandra J. Weisberg \\ Department of Botany and Plant Pathology, Oregon State University, Corvallis, \\ OR 97331
}

\author{
John G. Jelesko ${ }^{1}$ \\ Department of Plant Pathology, Physiology, and Weed Science, Virginia \\ Tech, 220 Ag Quad Lane, Blacksburg, VA 24061
}

Additional index words. Toxicodendron radicans, agroinfiltration, luciferase, biolistic transformation

\begin{abstract}
Poison ivy [Toxicodendron radicans (L.) Kuntz] is a widely recognized native plant species because of its production of urushiol, which is responsible for delayed contact dermatitis symptoms in humans. Poison ivy is predicted to become both more prevalent and more noxious in response to projected patterns of climate change. Future studies on poison ivy chemical ecology will require reverse genetics to investigate urushiol metabolism. A prerequisite for reverse genetic procedures is the introduction and expression of recombinant DNA into poison ivy tissues. Poison ivy leaves and cotyledons were marginally susceptible to vacuum- and syringe-agroinfiltration and expression of two firefly luciferase $(L U C)$-based reporter genes. The efficacy of agroinfiltration and transient $L U C$ expression was dependent on leaf age and plant growth environmental conditions, with young leaves grown in magenta boxes showing highest transient $L U C$ expression levels. Agroinfiltrated leaves showed an Agrobacteriumdependent accumulation of brown-colored pigments. Biolistic transformation of a $L U C$ reporter gene did not show brown pigment accumulation and readily displayed transient $L U C$ bioluminescence in both leaves and cotyledon tissues. These studies establish best practices for introducing and transiently expressing recombinant DNA into poison ivy leaf and cotyledon tissues, on which future reverse genetic procedures can be developed.
\end{abstract}

Poison ivy [Toxicodendron radicans (L.) Kuntz] is a native North American species best known for its capacity to induce allergenic dermatitis symptoms after contact with human skin. The natural product responsible for the dreaded skin rashes are alk(en)yl-catechol congeners generically called urushiol, which is found in all members of the Toxicodendron genus (Gross et al., 1975; Hill et al., 1934; Kurtz and Dawson, 1971; Majima, 1922; Markiewitz and Dawson, 1965; Symes and Dawson, 1953,

\footnotetext{
Received for publication 4 Oct. 2017. Accepted for publication 23 Dec. 2017

This work was supported by funds from the Virginia Agricultural Experiment Station and the USDA National Institute of Food and Agriculture, U.S. Department of Agriculture (Washington, DC). C.C.D. performed the syringe-agroinfiltration, biolistic transformation, and luciferase-imaging experiment data analysis, and writing and editing of the manuscript. A.J.W. performed the vacuum-agroinfiltration, luciferase imaging, and editing of manuscript. J.G.J. conceived and supervised the experiments, performed data analyses, and wrote the manuscript.

${ }^{1}$ Corresponding author. E-mail: jelesko@vt.edu.
}

alk(en)yl-catechol (urushiol) congeners. With that said, none of the proposed urushiol metabolites, enzyme activities, enzymes, or genes have been empirically validated to date. DeWick's hypothesized formation of a fatty acid tetraketide that is cyclized into an alkylphenol by a polyketide synthase activity is likely because a number of plant polyketide synthases use fatty acid-CoA starting molecules in the production of alkylphenols (Abe et al., 2004; Kim et al., 2010, 2013; Matsuzawa et al., 2010; Taura et al., 2016, 2009). The capacity to investigate poison ivy metabolism and chemical ecology was recently advanced with the publication of the poison ivy ( $T$. radicans) leaf and root transcriptome (Weisberg et al., 2017).

The capacity to express recombinant DNA molecules in plants enables detailed investigations of the role of both endogenous and foreign genes. Recombinant genes in plants can be expressed either as transient unintegrated transgenes or as transgenes that are stably integrated into the plant nuclear or plastid genomes. Understanding the molecular basis for urushiol biosynthesis and urushiol chemical ecology will require a variety of molecular genetic methods, all of which require the introduction and expression of recombinant DNA in poison ivy plant cells and tissues. The principle methods of introducing recombinant DNA constructs into plant cells are biolistic and Agrobacterium-based transformation procedures.

Agrobacterium tumefaciens was initially investigated as a soil-borne phytopathogen responsible for crown gall tumor formation. The etiology of pathology requires segments of bacterial tumorinducing $(\mathrm{Ti})$ plasmid DNA transfer, stable integration, and expression of these bacterial DNA sequences within the plant cell nucleus (Drummond et al., 1977). This inherent plant gene transformation capability of $A$. tumefaciens was reengineered to replace the tumor formation regions on the $\mathrm{Ti}$ plasmid (i.e., disarmed binary $\mathrm{Ti}$ plasmids) with recombinant "genes of interest." The potential utility of Agrobacteriummediated transient transformation was first demonstrated by expressing high levels of transient GUS reporter gene activity in bean, tobacco, and poplar leaves by simply infiltrating A. tumefaciens harboring a GUS reporter gene on a binary T-DNA plasmid directly into the leaf mesophyll interstitial space (Kapila et al., 1997). The general applicability of the technique is shown by transient reporter gene expression in the leaves of diverse plant species such as switchgrass (VanderGheynst et al., 2008), habanero pepper (Arcos-Ortega et al., 2010), cowpea epicotyl (Bakshi et al., 2011), rice (Andrieu et al., 2012), soybean (King et al., 2015), and persimmon (Mo et al., 2015), to name a few.

Biolistic transformation is often used when Agrobacterium-mediated transformation proves problematic. Biolistic transformation is the acceleration of nucleic acid-coated 
microparticles to high velocity (using a socalled gene gun) resulting in entry into the plant cell cytoplasm, where the nucleic acid subsequently uncoats from the microparticle, and is either transiently expressed or stably integrates into the plant nuclear genome (Klein et al., 1987). Alternatively, if combined with appropriate plastid DNA sequences the transgene can integrate into, and be expressed from, the plastid genome (Daniell et al., 1990). Biolistic transformation is the method of choice for stable transformation of major cereal crops (Klein et al., 1988; Wang et al., 1988) that are otherwise recalcitrant to Agrobacterium-mediated stable transformation.

Development of reverse genetic methods in poison ivy will enable molecular genetic investigations of poison ivy ecophysiology and chemical ecology, and provide foundational molecular genetic approaches in other members of the Toxicodendron genus (e.g., poison oak and poison sumac). As an initial step toward the implementation of such molecular genetic studies, the present report describes the introduction and transient expression of recombinant firefly $L U C$ reporter gene constructs in poison ivy cells and tissues through agroinfiltration and biolistic transformation.

\section{Materials and Methods}

Plant material. Poison ivy (T. radicans subsp. radicans) drupes were sourced from the RoaCo-1 liana located in Catawba VA (Benhase and Jelesko, 2013). Drupes were mechanically and chemically scarified (Benhase and Jelesko, 2013). Axenic seedlings were germinated on petri plates of $0.5 \mathrm{X}$ Murashige \& Skoog (MS) basal salts media (Plant Natural, Bozeman, MT), in the dark for four nights. Germinating seedlings were then transferred to either sterile $0.5 \mathrm{X}$ MS media in magenta boxes or pots containing nonsterile Sunshine Mix 1 (Plant Natural). The plants were grown at $28^{\circ} \mathrm{C}$ under $16 \mathrm{~h}$ light/day cycle. Poison ivy leaves were typically agroinfiltrated with a syringe at the three to four true leaf stage. Nicotiana benthamiana plants were directly germinated and grown in pots containing Sunshine Mix, under the same environmental conditions as the poison ivy seedlings. Nicotiana benthamiana plants were syringe agroinfiltrated 4 weeks postgermination.

Agroinfiltration transformation. Three $L U C$-containing plasmids were used in this study. Plasmid pJGJ204 contains an Arabidopsis $R B C S 1 B-L U C$ gene fusion comprised the $R B C S 1 B$ promoter-exon 3 , resulting in an in-frame $R B C S 1 B-L U C$ chimeric fusion protein (Jelesko et al., 1999). The firefly $L U C$ was polymerase chain reaction (PCR) amplified from pJGJ102 (Jelesko et al., 1999) using oligonucleotide primers (oJGJ234 5'-GGGGAGAAGTTTGTACAAAAAAGCAGGCTATGGAAGACGCCAAAAACATA-3' ; and oJGJ235 5'-GGGGACCACTTTGTACAAGAAAGCTGGGTATTTTACAATTTGGACTTTC-3') that incorporated $5^{\prime}-$ attB1 and $3^{\prime}$-attB2 sequences. The resulting $L U C$ PCR fragment was BP subcloned into pDONR221 using BP Clonase II (Thermofisher, Waltham, MA) to yield plasmid pJGJ404. The $L U C$ gene from pJGJ404 was subcloned into pMCD32 (Curtis and Grossniklaus, 2003) using LR Clonase II (Invitrogen, Carlsbad, CA) to yield plasmid pJGJ410 expressing the $L U C$ gene from a double CaMV35S promoter. Plasmid pJGJ411 containing a $L U C-I N T$ gene was similarly subcloned, except using pLUK07 (Mankin et al., 1997) as the template in the initial PCR reaction. Plasmid p19 (Voinnet et al., 2003) was used for enhancing transient expression levels of the transgenes in plant cells. Agrobacterium tumefaciens strain GV3101 containing either p19 (Voinnet et al., 2003), pJGJ204, pJGJ410, or pJGJ411 were grown overnight $(16 \mathrm{~h})$ in $5 \mathrm{~mL}$ LuriaBertani medium supplemented with 50 $\mu \mathrm{g} \cdot \mathrm{mL}^{-1}$ kanamycin and $50 \mu \mathrm{g} \cdot \mathrm{mL}^{-1}$ gentamycin. The culture optical density (OD) at 600 $\mathrm{nm}\left(\mathrm{OD}_{600}\right)$ was estimated from a 1:10 culture dilution before initial centrifugation ( $15 \mathrm{~min}$ at $4{ }^{\circ} \mathrm{C}, 3000 \times g$ ). Cultures were resuspended in MMA buffer [10 mM 2-N-Morpholino ethanesulfonic acid (MES), $10 \mathrm{~mm} \mathrm{MgCl}_{2}$, and 20 $\mu \mathrm{M}$ acetosyringone] by vortexing for either final $\mathrm{OD}_{600}$ of 4.0 or 0.4 . The Agrobacterium strains containing a $L U C$-containing plasmid (pJGJ204, pJGJ410, or pJGJ411) were mixed with GV3101/p19 at equivalent concentration and incubated at $22{ }^{\circ} \mathrm{C}$ for $1 \mathrm{~h}$ before agroinfiltration (Kapila et al., 1997). Leaf tissues were either vacuum-agroinfiltrated or syringeagroinfiltrated using a $3 \mathrm{~mL}$ Luer Lok syringe (Becton Dickinson, Franklin Lakes, NJ), on the leaf underside (Kapila et al., 1997). Plants were returned to a $28^{\circ} \mathrm{C}$ growth chamber for $24 \mathrm{~h}$ before assay of $L U C$ activity.

Biolistic-mediated transformation. Plasmid pJGJ411 was isolated from Escherichia coli OmniMax strain first by large scale alkaline lysis (Ausubel et al., 2006), then purification using a QIAprep Miniprep kit (Qiagen, Valencia, CA). Purified pJGJ411 plasmid DNA was coated on $(0.6 \mu \mathrm{m})$ gold particles, accelerated using a 1100 psi rupture disk (Analytical Scientific Instruments US Inc., Richmond, CA) in a Bio-Rad (Richmond, CA) Biolistic PDS-1000 He Particle Delivery System. Poison ivy cotyledon/first true leafstage seedlings in magenta boxes were subjected to particle bombardment at a distance of $\approx 13 \mathrm{~cm}$. After bombardment, plants were returned to a $28{ }^{\circ} \mathrm{C}$ growth chamber for $24 \mathrm{~h}$ before assay of $L U C$ activity.

Luciferase assay. Before LUC imaging, transformed poison ivy tissues were placed onto water agar plates and then sprayed with luciferin and subjected to in vivo $L U C$ imaging, as previously described (Jelesko et al., 1999). Qualitative photon emission imaging was obtained from "slice" images. Quantification of vacuum-agroinfiltration and biolistic-transformed poison ivy cotyledon and first true leaf in vivo-LUC activity (photon emission) was estimated using "gravity" images. A fixed area defined by the area that encompassed either the largest cotyledon $\left(6358\right.$ pixels $\left.^{2}\right)$ or largest first true leaf $\left(30,458\right.$ pixels $\left.^{2}\right)$ was used to measure the number of emitted photons for each subsequent cotyledon, leaf, and background. The background heat photon emission was estimated for each specified tissue by randomly measuring the apparent gravity photon emission in 10 regions corresponding to the absence of poison ivy tissue in the reflected light images, and the upper $95 \%$ confidence interval value was calculated. The upper $95 \%$ confidence interval value established the upper boundary of background heat photon emission levels corresponding to cotyledon and leaves, respectively. The respective upper background photon emission value was subtracted from the value of the respective tissue's highest photon emission level, and the resulting difference was equally divided into five bins, thereby providing a rough distribution of photon emission levels for each transformed tissue.

\section{Results}

Transient LUC-INT gene expression in poison ivy leaves using syringe agroinfiltration. Poison ivy leaves were subjected to syringeagroinfiltration using $A$. tumefaciens strain GV3101 harboring plasmid pJGJ411 containing a double CaMV promoter driving the expression of firefly $L U C$ gene containing an artificial intron ( $L U C-I N T)$. The intron in the $L U C-I N T$ gene abolished low expression levels in Agrobacterium cells relative to the continuous $L U C$ open reading frame in pJGJ410 (Supplemental Fig. 1), and thus all LUC activity was derived from transient $L U C$ expression in poison ivy cells. Poison ivy leaves from potting soil-grown plants subjected to syringe-agroinfiltration generally did not display $L U C$ activity greater than background heat photon emission levels in qualitative pseudocolor superimposed slice photon emission images (Fig. 1A). On very few occasions weak photon emission more than background levels of syringe-agroinfiltrated leaves was observed. In contrast, syringe-Aagroinfiltrated leaves on poison ivy plants grown axenically in magenta boxes displayed small patches of consistent photon emission over regions that were syringe-agroinfiltrated (Fig. 1A). Thus, magenta box-grown poison ivy leaves were more susceptible to syringe-agroinfiltrationmediated transient DNA transformation. However, not all leaves from Magenta box grown poison ivy plants were equally susceptible to syringe-agroinfiltration. Older leaves of magenta box-grown plants were less susceptible to syringe-agroinfiltration transient $L U C-I N T$ expression compared with younger leaves (Fig. 1B). Younger leaves more readily took up the Agrobacterium-infiltration solution delivered from the blunt syringe. Consequently, young poison ivy leaves in magenta boxgrown plants consistently showed higher transient $L U C$ expression levels than older leaves from the same plants, whereas changing the bacterial concentration 10 -fold had little effect on transient $L U C$ expression levels (Supplemental Fig. 4). With that said, even the best poison ivy transient $L U C$ expression levels were dramatically lower than $N$. benthamiana leaves syringe-agroinfiltrated with pJGJ411 (Fig. 1C). The poison ivy 

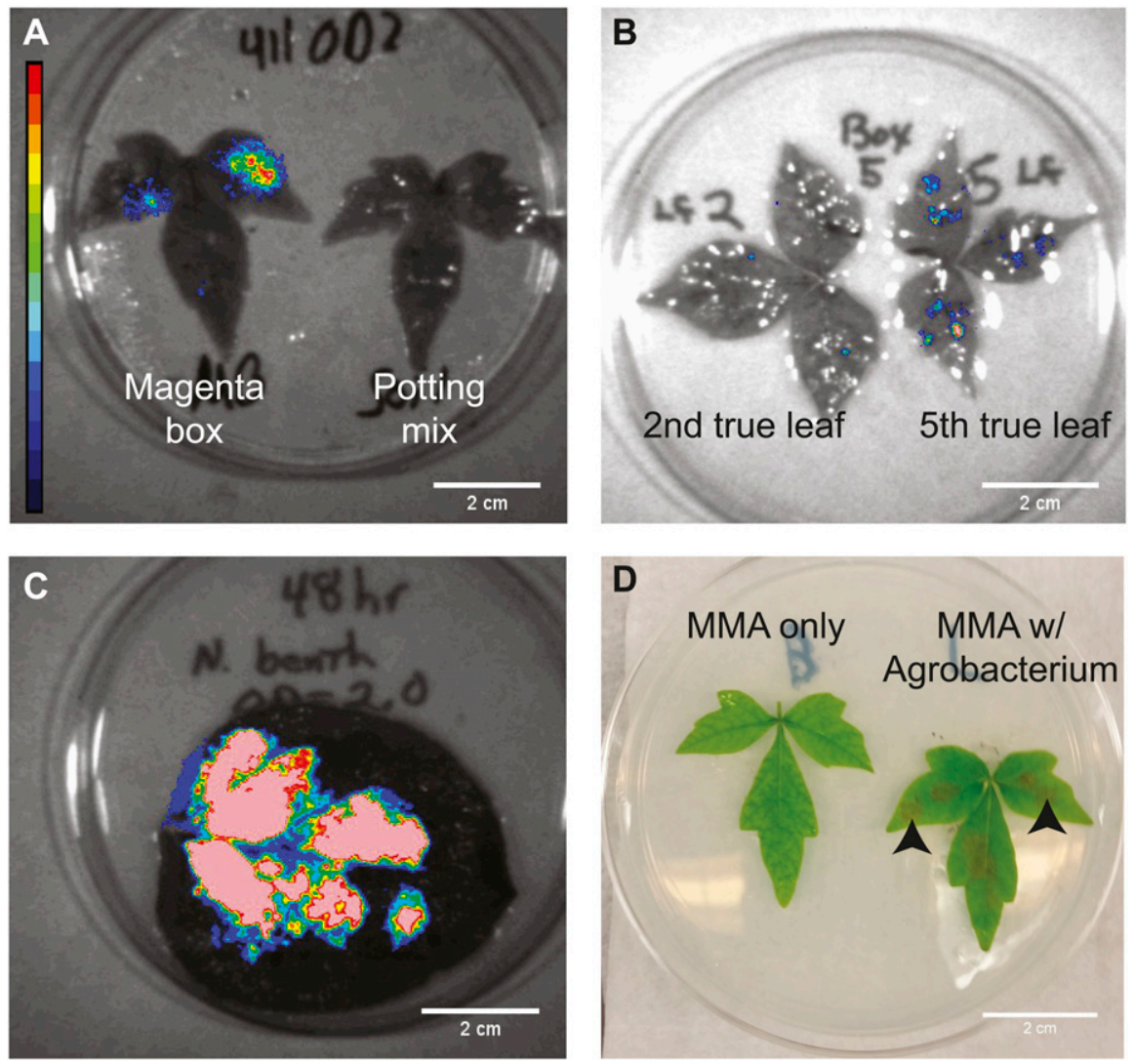

Fig. 1. Imaging of agroinfiltrated leaves. Panels $\mathbf{A}-\mathbf{C}$ single photon pseudocolor images (panel $\mathbf{A}$ inset is pseudocolor step gradient with high photon emission shown as red to low photon emission as dark blue) superimposed on reflected light image (grayscale). Panel D, digital color image of poison ivy leaves infiltrated with either MMA buffer or MMA buffer with Agrobacterium containing the firefly LUC construct. Arrows indicate browning at site of agroinfiltration. (A and $\mathbf{B}$ ) Composite pseudocolor single photon imaging on reflected light image of poison ivy leaves agroinfiltrated with firefly $L U C$ construct. (C) Nicotiana benthamiana leaf similarly agroinfiltrated and imaged.

leaves did not take up as much of the Agrobacterium solution as the $N$. benthamiana leaves with each syringe-agroinfiltration attempt. However, these differences in relative infiltration volumes were far less than the difference in magnitude of photon emission between poison ivy and $N$. benthamiana (Fig. 1A and C).

Syringe-agroinfiltrated poison ivy leaves displayed brown discoloration within the regions that were effectively infiltrated with bacteria (Fig. 1D). This brown discoloration was dependent on the presence of the Agrobacterium, because syringe infiltration with just the MMA media lacking $A$. tumefaciens did not acquire the brown pigmentation. When plants are infiltrated with bacteria, many plant species induce the synthesis and accumulation of phytoalexin compounds as part of a plant defense response (Hammerschmidt, 1999). Thus, the overall low transient $L U C$ expression levels may have been a consequence of reduced Agrobacterium vigor in response to a biotic stress response, however this possibility was not further investigated in this study.

Transient AtRBCS1B-LUC gene expression in poison ivy leaves using vacuumagroinfiltration. Vacuum-agroinfiltration was investigated as an alternative method for transient heterologous plant gene expression in poison ivy. An Arabidopsis chimeric
AtRBCS1B-LUC chimeric gene fusion (pJGJ204 comprised the AtRBCSIB promoter, exons I, fused in-frame to the firefly $L U C$ open reading frame), was used to vacuum-agroinfiltrate excised poison ivy leaves and cotyledons from plants grown in magenta boxes. Vacuumagroinfiltrated leaves were placed on $0.5 \times \mathrm{MS}$ media plates, sprayed with luciferin at $24 \mathrm{~h}$ postinfiltration, and then imaged for three sepost agroinfiltration. The AtRBCS1B-LUC chimeric gene produces a low rate of photon emission in transgenic Arabidopsis plants. Superimposed "slice" images with complete subtraction of background photons displayed a few blue spots over leaves/cotyledons (Supplemental Fig. 2A), whereas superimposed "slice" imaging that retained some background photons displayed higher qualitative photon accumulation over leaves vacuum-agroinfiltrated with the plasmid containing the AtRBCS1B-LUC chimeric gene, relative to vacuum-agroinfiltrations with the vector control plasmid pSLK7292 (Supplemental Fig. 2B) indicating low but demonstrable AtRBCS1B-LUC recombinant protein expression over background heat photons. Photon emission levels were significantly higher in pJGJ204 (AtRBCS1B-LUC) vacuum-agroinfiltrated leaves and cotyledons compared with pSLK7292 vacuum-agroinfiltrated leaves and cotyledons intron I, exon II, intron II, and partial exon III quential $1 \mathrm{~h}$-imaging sessions beginning at $\approx 48 \mathrm{~h}$
( $P$ value $<0.05$ ), during the first two of three sequential $1 \mathrm{~h}$-imaging sessions quantified using "gravity" imaging (Fig. 2). There was a consistent trend of gradually lower total photon emission levels over the course of three hours suggesting that luciferin substrate levels were a limiting factor during the imaging session. The vacuumagroinfiltrated leaves and cotyledons also showed browning of infiltrated tissues similar to the syringe-agroinfiltrated leaves. This was particularly apparent in cases where the cotyledon or leaf segments were not fully vacuum-agroinfiltrated, and showed a lighter green color (see arrows in Supplemental Fig. 2C) typical of uninfiltrated leaves. These results demonstrate that a heterologous Arabidopsis genomic $R B C S 1 B$ promoter and intron containing $R B C S 1 B-L U C$ gene fusion was expressed in poison ivy leaves and cotyledons.

Biolistic transient LUC gene expression in poison ivy leaves and cotyledons. The induction of an apparent biotic stress response (i.e., accumulation of brown pigmentation) in agroinfiltrated poison ivy leaf tissue might limit the efficiency of agroinfiltration transient DNA transformation. To avoid such a possibility, biolistic transformation of isolated pJGJ411 (LUC-INT) plasmid DNA directly into poison ivy leaves and cotyledons was investigated. Using superimposed slice photon imaging, punctuate foci of photon emission were observed on both cotyledons and leaves (Supplemental Fig. 3). The distribution of $L U C$ expression was not uniform, both across tissue type and between replicated tissues on the same targeting field. Likewise, quantification of gravity images demonstrated that the amount of photon emission from any given leaf or cotyledon was variable, ranging from background heat photons to quite intense photon emission (Fig. 3). This variability is likely a consequence of the uneven and unpredictable spreading of plasmid-coated gold particles during particle acceleration. Unlike all poison ivy tissues transformed by agroinfiltration, the biolistic transformed poison ivy cotyledons and leaf tissues did not produce demonstrable brown pigmentation.

\section{Discussion}

These studies lay the foundation for future transgenic reverse genetic approaches to investigate various poison ivy physiologies by demonstrating that exogenous DNA can be effectively introduced and expressed in poison ivy cotyledon and leaf tissues. Because the CaMV35S promoter is weakly active in A. tumefaciens (Supplemental Fig. 1; Mankin et al., 1997) it was essential to use introncontaining firefly $L U C$ gene constructs (CaMV35S-LUC-INT and AtRBCS1B-LUC) to validate poison ivy-specific transient $L U C$ activity. This was particularly germane in the case of the AtRBCS1B-LUC construct used in the vacuum-agroinfiltrated leaves and cotyledons because this reporter gene construct is expressed at relatively low levels in plant cells (Jelesko et al., 1999, 2004). The two introns in the AtRBCSIB-LUC gene ensured that all 


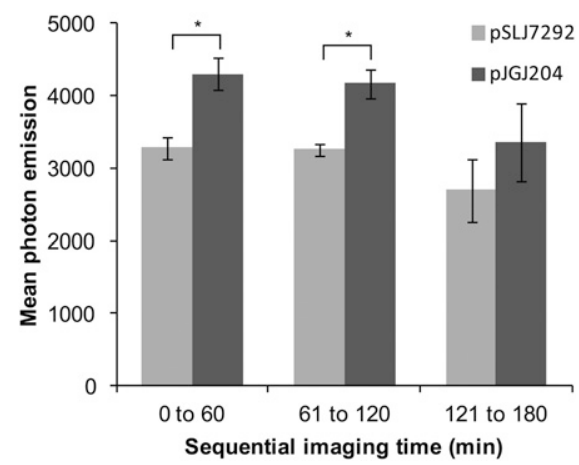

Fig. 2. Transient AtRBCS1B-LUC expression in vacuum-agroinfiltrated poison ivy cotyledons and leaves. Leaves were imaged at $48 \mathrm{~h}$ post vacuum-agroinfiltration for three consecutive $1 \mathrm{~h}$-imaging sessions. The experiment was replicated two times. The mean photon emission values were plotted with standard error, and asterisks indicates $P$ value $\leq 0.05$ in two-sample $t$ test comparing vector control (pSLK7292) with AtRBCS1B-LUC binary plasmid pJGJ204.

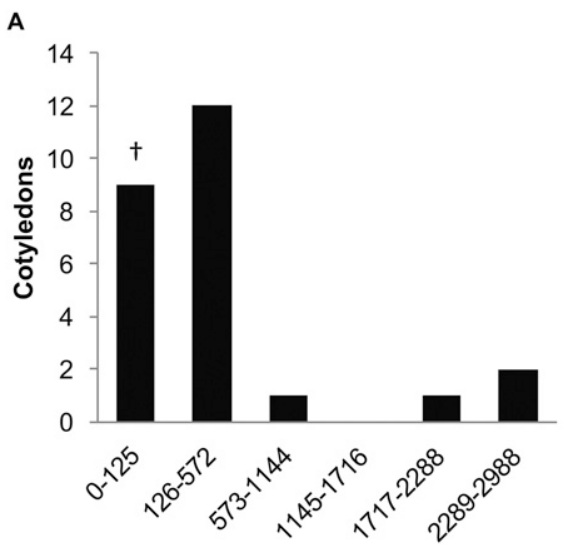

Photons emitted per cotyledon

B

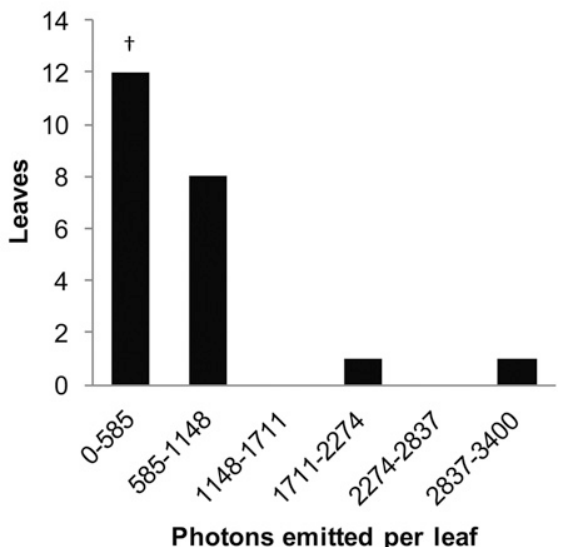

Fig. 3. The number of cotyledons or leaves with a specified range of photons emitted on a per leaf or per cotyledon basis. The dagger ( $\dagger$ ) indicates the background photon emission bin for cotyledons (panel A) and leaves (panel B), see Materials and Methods section for calculation of background photon emission levels.

$L U C$ activity was due to expression in transiently transformed poison ivy cells and not within the A. tumefaciens strain GV3101.
The age of poison ivy leaves was an important factor for the relative susceptibility of syringe agroinfiltration transient transformation. Leaves from potting soil-grown poison ivy plants were mostly recalcitrant to syringe-agroinfiltration transient transformation. On the other hand, young poison ivy leaves from plants grown in magenta boxes showed consistent syringe-agroinfiltration transient $L U C-I N T$ expression. Moreover, overall plant age was not the critical determinant, but rather the relative age of target leaves. As shown in Fig. 1B, the fifth emerged leaf (young leaf) showed greater syringe-agroinfiltration transient $L U C$ expression levels than that of the second emerged leaf (older leaf) on the same plant. The qualitative levels of $L U C-I N T$ expression levels in poison ivy leaves were dramatically lower than the levels observed in $N$. benthamiana leaves syringe-agroinfiltrated with the same reporter gene construct. Poison ivy cotyledons and leaves were also susceptible to vacuum-agroinfiltration transient transformation using a chimeric $A t R B C S 1 B$ $L U C$ transgene. Leaves infiltrated with $A$. tumefaciens strain GV3101 displayed discoloration consistent with an inducible plant biotic stress response. Both syringe- and vacuum-agroinfiltrated leaves demonstrated the accumulation of uncharacterized brown pigments (Fig. 1D; Supplemental Fig. 2C). This pigment accumulation was not observed for leaves infiltrated with MMA buffer lacking Agrobacteria (Fig. 1D). The relative LUC expression levels in the brightest poison ivy leaves was dramatically less that that observed in control $N$. benthamiana leaves syringe agroinfiltrated with the same construct. This difference could have been due to a variety of parameters including the quantity of Agrobacteria penetrating into the apoplastic space of leaves, and/or a biotic stress response that inhibited bacterial vigor or T-DNA transfer into the plant cells. Nevertheless, poison ivy leaves and cotyledons showed significant transient $L U C-I N T$ and $A t R B C S 1 B-L U C$ expression levels over controls indicating the feasibility of using agroinfiltration transient poison ivy transformation.

As expected, poison ivy cotyledons and leaves were readily transiently transformed using a biolistic method. Biolistically transformed poison ivy leaves and cotyledons did not produce brown pigmented regions and thus averted a poison ivy biotic stress response against bacterial pathogen associated molecular patterns. As is typical of biolistic transformation of plant tissues, the transient $L U C-I N T$ expression levels were highly variable among both leaf and cotyledon tissues. This is in large part to previously recognized inconsistencies in both plasmid DNA coating of gold micro particles (Sanford et al., 1993) and heterogenous particle spread on the macro carrier disk, resulting in heterogeneous distribution during particle acceleration toward the target tissue.

These results demonstrate the feasibility of poison ivy leaf and cotyledon transient transformation with recombinant reporter gene constructs using either agroinfiltration or biolistic methods. Both poison ivy DNA transformation methods are important technical advancements enabling the introduction of recombinant DNA constructs designed for a variety of reverse genetic (e.g., RNA interference or viral induced gene silencing) and genome-editing methods (e.g., zinc finger, TALEN, or CRISPR-CAS9) to enable molecular genetic investigations of poison ivy ecophysiology and metabolism.

\section{Literature Cited}

Abe, I., Y. Utsumi, S. Oguro, and H. Noguchi. 2004. The first plant type III polyketide synthase that catalyzes formation of aromatic heptaketide. FEBS Lett. 562:171-176.

Andrieu, A., J.C. Breitler, C. Sire, D. Meynard, P. Gantet, and E. Guiderdoni. 2012. An in planta, Agrobacterium-mediated transient gene expression method for inducing gene silencing in rice (Oryza sativa L.) leaves. Rice (NY) 5:23.

Arcos-Ortega, G.F., R.A. Chan-Kuuk, W.A. GonzalezKantun, R. Souza-Perera, Y.E. Nakazawa-Ueji, E. Aviles-Berzunza, G. Godoy-Hernandez, M.A. Lawton, and J.J.Z. Aguilar. 2010. Agrobacterium tumefaciens-transient genetic transformation of Habanero pepper (Capsicum chinense Jacq.) leaf explants. Electron. J. Biotechnol. 13:10.

Ausubel, F.A., R. Brent, R.E. Kingston, D.D. Moore, J.G. Seidman, J.A. Smith, and K. Struhl. 2006. Current protocols in molecular biology. Wiley, New York, NY.

Bakshi, S., A. Sadhukhan, S. Mishra, and L. Sahoo. 2011. Improved Agrobacterium-mediated transformation of cowpea via sonication and vacuum infiltration. Plant Cell Rep. 30:2281-2292.

Benhase, E.B. and J.G. Jelesko. 2013. Germinating and culturing axenic poison ivy seedlings. HortScience 48:1525-1529.

Curtis, M.D. and U. Grossniklaus. 2003. A gateway cloning vector set for high-throughput functional analysis of genes in planta. Plant Physiol. 133:462-469.

Daniell, H., J. Vivekananda, B.L. Nielsen, G.N. Ye, K.K. Tewari, and J.C. Sanford. 1990 Transient foreign gene expression in chloroplasts of cultured tobacco cells after biolistic delivery of chloroplast vectors. Proc. Natl. Acad. Sci. USA 87:88-92.

Dewick, P.M. 1997. Medicinal natural products: A biosynthetic approach. Wiley, Chichester, UK.

Drummond, M.H., M.P. Gordon, E.W. Nester, and M.D. Chilton. 1977. Foreign DNA of bacterial plasmid origin is transcribed in crown gall tumours [Agrobacterium tumefaciens]. Nature 269:535-536.

Gross, M., H. Baer, and H.M. Fales. 1975. Urushiols of poisonous anacardiaceae. Phytochemistry 14:2263-2266.

Hammerschmidt, R. 1999. Phytoalexins: What have we learned after 60 years? Annu. Rev. Phytopathol. 37:285-306

Hill, G.A., V. Mattacotti, and W.D. Graha. 1934. The toxic principle of the poison ivy. J. Amer. Chem. Soc. 56:2736-2738.

Jelesko, J.G., K. Carter, W. Thompson, K. Kinoshita, and W. Gruissem. 2004. Meiotic recombination between paralogous $R B C S B$ genes on sister chromatids of Arabidopsis thaliana. Genetics 166:947-957.

Jelesko, J.G., R. Harper, M. Furuya, and W. Gruissem. 1999. Rare germinal unequal crossingover leading to recombinant gene formation and gene duplication in Arabidopsis thaliana. Proc. Natl. Acad. Sci. USA 96:10302-10307. 
Kapila, J., R. DeRycke, M. VanMontagu, and G. Angenon. 1997. An Agrobacterium-mediated transient gene expression system for intact leaves. Plant Sci. 122:101-108.

Kim, S.S., E. Grienenberger, B. Lallemand, C.C. Colpitts, S.Y. Kim, A. Souza Cde, P. Geoffroy, D. Heintz, D. Krahn, M. Kaiser, E. Kombrink, T. Heitz, D.Y. Suh, M. Legrand, and C.J. Douglas. 2010. LAP6/POLYKETIDE SYNTHASE $A$ and LAP5/POLYKETIDE SYNTHASE $B$ encode hydroxyalkyl alpha-pyrone synthases required for pollen development and sporopollenin biosynthesis in Arabidopsis thaliana. Plant Cell 22:4045-4066.

Kim, S.Y., C.C. Colpitts, G. Wiedemann, C. Jepson, M. Rahimi, J.R. Rothwell, A.D. McInnes, M. Hasebe, R. Reski, B.T. Sterenberg, and D.Y. Suh. 2013. Physcomitrella PpORS, basal to plant type III polyketide synthases in phylogenetic trees, is a very long chain 2 ' -oxoalkylresorcinol synthase. J. Biol. Chem. 288:2767-2777.

King, J.L., J.J. Finer, and L.K. McHale. 2015. Development and optimization of agroinfiltration for soybean. Plant Cell Rep. 34:133140.

Klein, T.M., M. Fromm, A. Weissinger, D. Tomes, S. Schaaf, M. Sletten, and J.C. Sanford. 1988 Transfer of foreign genes into intact maize cells with high-velocity microprojectiles. Proc. Natl. Acad. Sci. USA 85:4305-4309.

Klein, T.M., E.D. Wolf, R. Wu, and J.C. Sanford 1987. High-velocity microprojectiles for delivering nucleic-acids into living cells. Nature 327:70-73.

Kurtz, A.P. and C.R. Dawson. 1971. Synthesis of compounds structurally related to poison ivy urushiol. 4. 3-(1-Alkyl)alkylcatechols of varying side-chain shape and flexibility. J. Med. Chem. 14:733-737.

Majima, R. 1922. Uber den hauptbestandteil des Japan-lacs, VIII. Mitteilung: Stellung der doppelbindungen in der seitenkette des urushiols und beweisfuhrung, dab das urushiol eine mischung ist. Ber. Dtsch. Chem. Ges. 55 (b):172-191.

Mankin, S.L., G.C. Allen, and W.F. Thompson 1997. Introduction of a plant intron into the luciferase gene of Photinus pyralis. Plant Mol. Biol. Rpt. 15:186-196.

Markiewitz, K.H. and C.R. Dawson. 1965. On the isolation of the allegenically active components of the toxic principle of poison ivy. J. Org. Chem. 30:1610-1613.

Martin, A.C., H.S. Zim, and A.L. Nelson. 1951. American wildlife \& plants. Dover Publications, Inc., New York, NY.

Matsuzawa, M., Y. Katsuyama, N. Funa, and S. Horinouchi. 2010. Alkylresorcylic acid synthesis by type III polyketide synthases from rice Oryza sativa. Phytochemistry 71:10591067.

Mo, R.L., Y.M. Huang, S.C. Yang, Q.L. Zhang, and Z.R. Luo. 2015. Development of Agrobacterium-mediated transient transformation in persimmon (Diospyros kaki Thunb.). Scientia Hort. 192:29-37.

Mohan, J.E., L.H. Ziska, W.H. Schlesinger, R.B Thomas, R.C. Sicher, K. George, and J.S Clark. 2006. Biomass and toxicity responses of poison ivy (Toxicodendron radicans) to elevated atmospheric $\mathrm{CO}_{2}$. Proc. Natl. Acad. Sci. USA 103:9086-9089.

Popay, I. and R. Field. 1996. Grazing animals as weed control agents. Weed Technol. 10:217231.

Sanford, J.C., F.D. Smith, and J.A. Russell. 1993. Optimizing the biolistic process for different biological applications. Methods Enzymol. 217:483-509.

Symes, W.F. and C.R. Dawson. 1953. Separation and structural determination of the olefinic components of poison ivy urushiol, cardanol and cardol. Nature 171:841-842.
Symes, W.F. and C.R. Dawson. 1954. Poison ivy "urushiol". J. Amer. Chem. Soc. 76:29592963.

Taura, F., M. Iijima, E. Yamanaka, H. Takahashi, H. Kenmoku, H. Saeki, S. Morimoto, Y. Asakawa, F. Kurosaki, and H. Morita. 2016. A novel class of plant type III polyketide synthase involved in orsellinic acid biosynthesis from Rhododendron dauricum. Front. Plant Sci. 7:1452.

Taura, F., S. Tanaka, C. Taguchi, T. Fukamizu, H. Tanaka, Y. Shoyama, and S. Morimoto. 2009. Characterization of olivetol synthase, a polyketide synthase putatively involved in cannabinoid biosynthetic pathway. FEBS Lett. 583:20612066.

VanderGheynst, J.S., H.Y. Guo, and C.W. Simmons. 2008. Response surface studies that elucidate the role of infiltration conditions on Agrobacterium tumefaciens-mediated transient transgene expression in harvested switchgrass (Panicum virgatum). Biomass Bioenergy 32:372-379.

Voinnet, O., S. Rivas, P. Mestre, and D. Baulcombe. 2003. An enhanced transient expression system in plants based on suppression of gene silencing by the p19 protein of tomato bushy stunt virus. Plant J. 33:949-956.

Wang, Y.C., T.M. Klein, M. Fromm, J. Cao, J.C. Sanford, and R. Wu. 1988. Transient expression of foreign genes in rice, wheat and soybean cells following particle bombardment. Plant Mol. Biol. 11:433-439.

Weisberg, A.J., G. Kim, J.H. Westwood, and J.G. Jelesko. 2017. Sequencing and de novo assembly of the Toxicodendron radicans (poison ivy) transcriptome. Genes (Basel) 8:317.

Ziska, L.H., R.C. Sicher, K. George, and J.E. Mohan. 2007. Rising atmospheric carbon dioxide and potential impacts on the growth and toxicity of poison ivy (Toxicodendron radicans). Weed Sci. 55:288-292. 


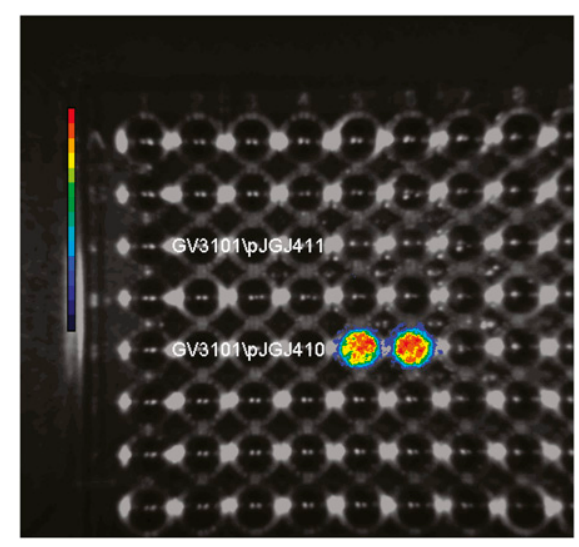

Supplemental Fig. 1. Superimposed photon emission images of Agrobacterium tumefaciens strains GV3103/pJGJ411 (LUC-INT reporter gene, wells C5-6) and GV3101/pJGJ410 (LUC reporter gene, wells E5-6) duplicate cultures placed in a 96-well microtiter plate. Pseudocolor step gradient is the same as Fig. 1A.

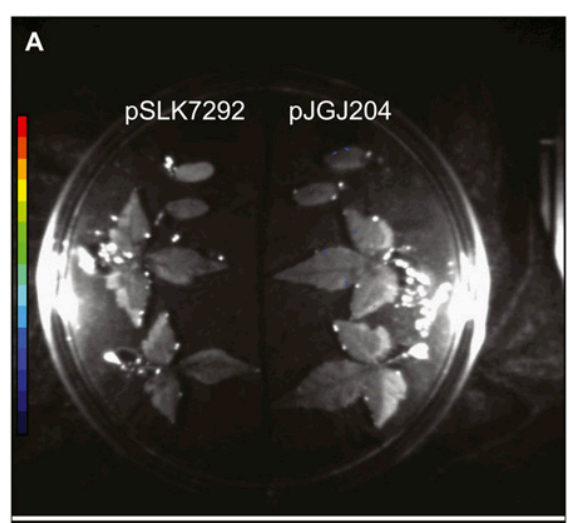

B

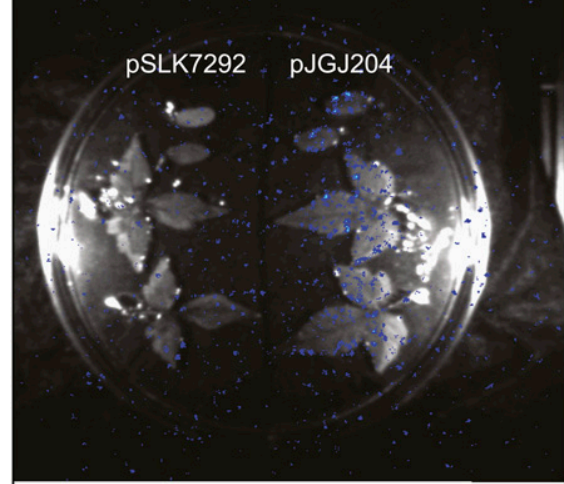

c

C $\quad$ pSLK7292

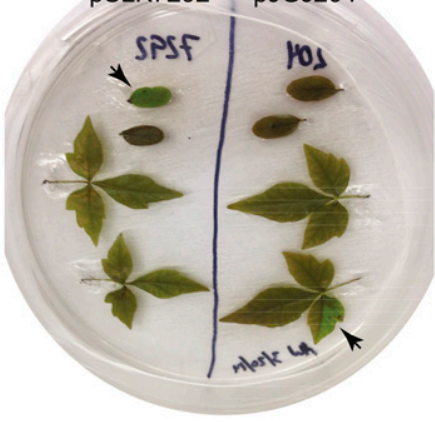

Supplemental Fig. 2. Poison ivy cotyledons and leaves vacuum-infiltrated with Agrobacterium tumefaciens harboring either empty vector (pSLK7292) or AtRBCS1B-LUC (pJGJ204). (A) Composite pseudocolor photon image with background heat photon levels subtracted. Pseudocolor step gradient is the same as Fig. 1A. (B) Composite pseudocolor photon image with background heat photon levels displayed. (C) Digital color image displaying mostly water-soaked infiltrated tissues and noninfiltrated tissues (indicated by arrows pointing toward lighter green noninfiltrated tissues). 

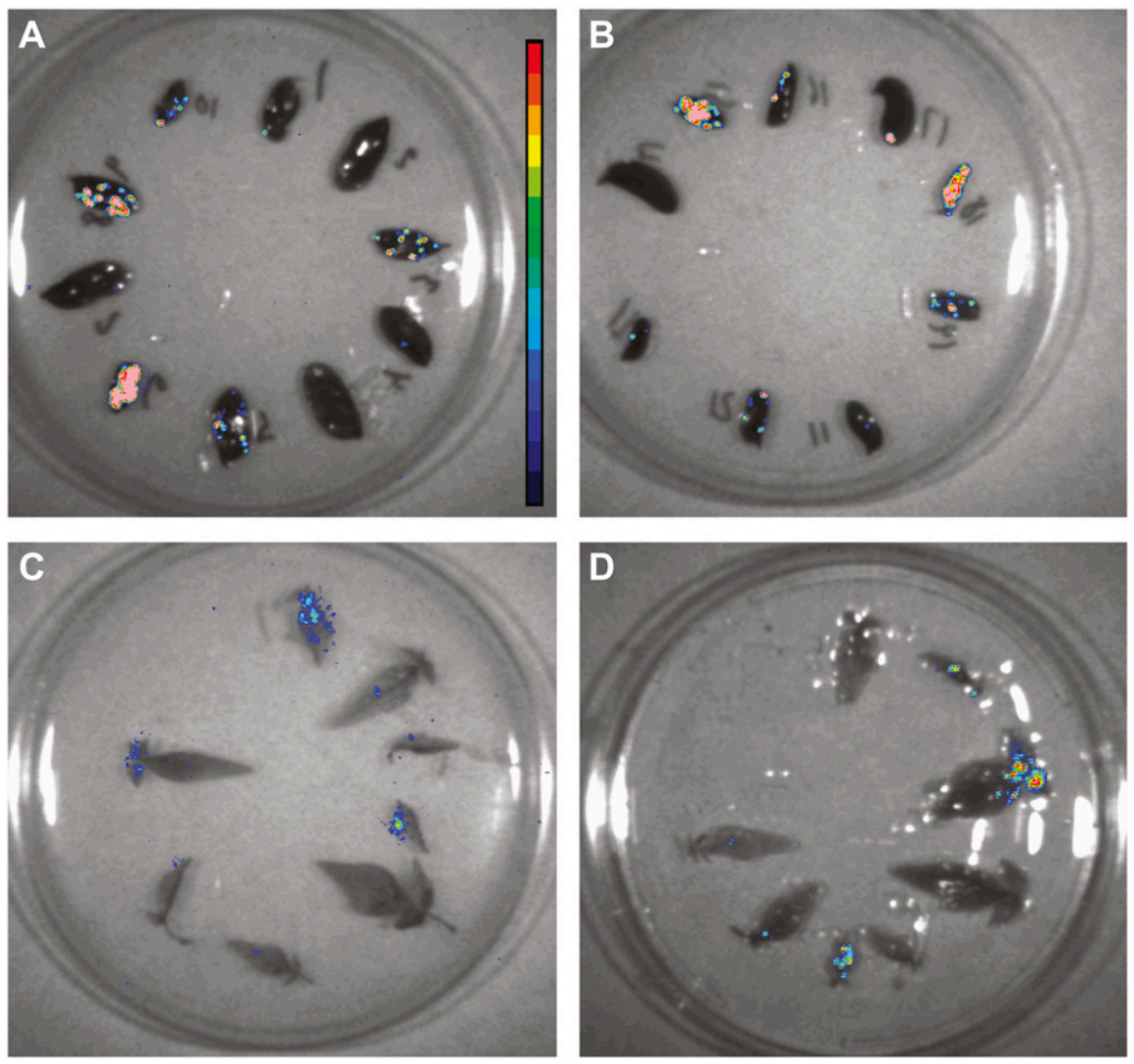

Supplemental Fig. 3. Superimposed photon emission of cotyledons (A and $\mathbf{B})$ and true leaves $(\mathbf{C}$ and $\mathbf{D})$ on reflected light image. Pseudocolor step gradient is the same as Fig. 1A.

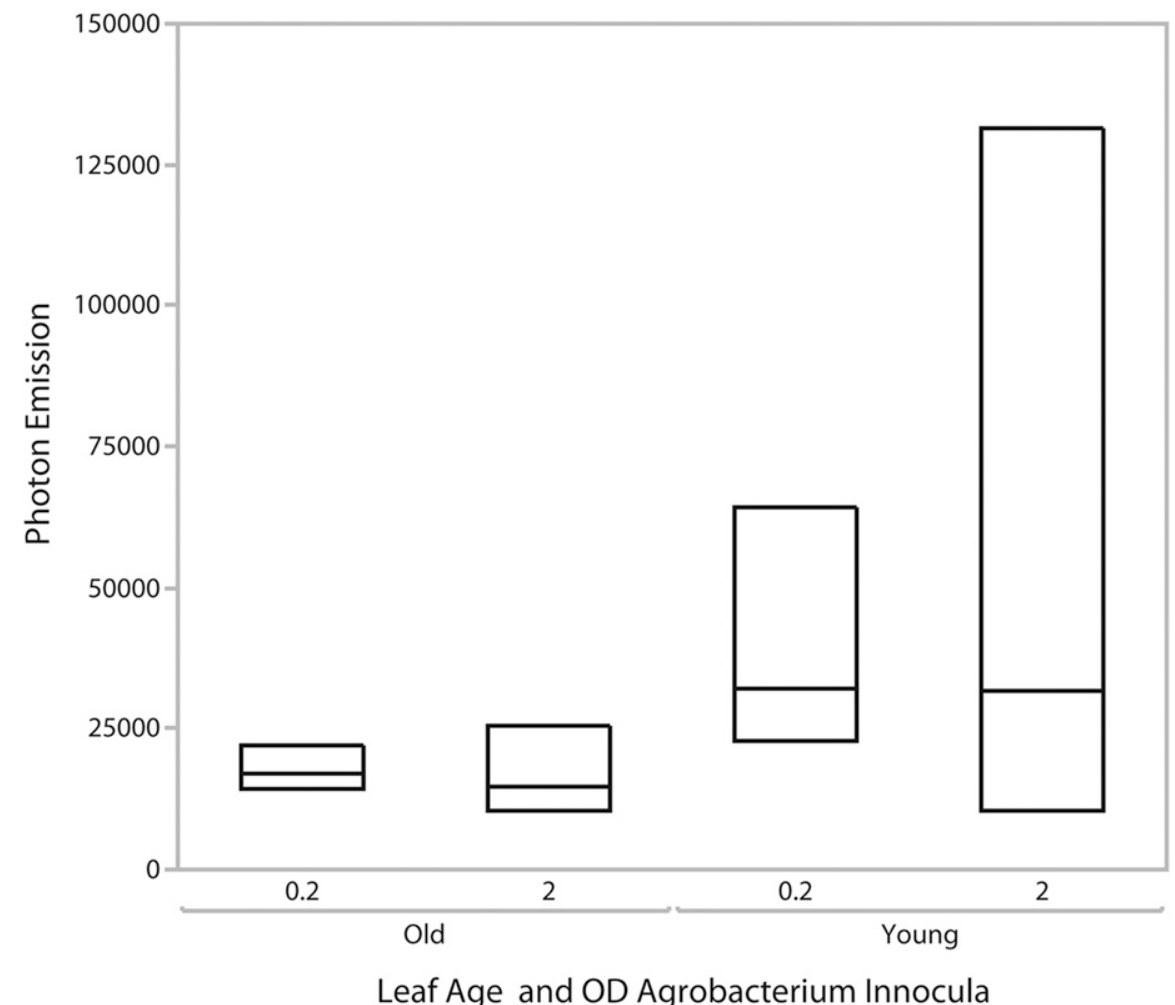

Supplemental Fig. 4. Box plots of photon emission levels from poison ivy leaves of different age and Agrobacterium inoculum concentrations. Leaves were from magenta box-grown poison ivy plants. Three leaves were independently imaged for each treatment combination. The line bisecting each box is the median value. Agrobacterium inoculum concentration was either $0.2 \mathrm{OD}$ or $2.0 \mathrm{OD}$ at $600 \mathrm{~nm}$. 